\title{
A CASE OF PRIMARY MEDIASTINAL ECTOPIC THYROID SUPPLIED BY THE BRACHIOCEPHALIC TRUNK
}

Bikram Haldar', Bitan Kumar Chattopadhyay ${ }^{2}$

1 Postgraduate Trainee, Department of General Surgery, IPGME and R, Kolkata.

2Professor and HOD, Department of General Surgery, IPGME and R, Kolkata.

HOW TO CITE THIS ARTICLE: Haldar B, Chattopadhyay BK. A case of primary mediastinal ectopic thyroid supplied by the brachiocephalic trunk. J. Evolution Med. Dent. Sci. 2018;7(01):122-124, DOI: 10.14260/jemds/2018/26

\section{PRESENTATION OF THE CASE}

An ectopic thyroid is a thyroid tissue that is not located anterolaterally to the $2^{\text {nd }}$ to $4^{\text {th }}$ tracheal cartilages due to faulty development.

It can be present anywhere along the path of embryological descent. It is often seen in lingual, sublingual and prelaryngeal locations.

Mediastinal ectopic thyroid is very rare, seen in less than $1 \%$ of all cases. ${ }^{1}$ Mediastinal thyroid must be differentiated from germ cell tumours, lymphomas, neurogenic tumours, thymic tumours, ganglioneuromas and cervical goitre extending into the mediastinum.2,3,4

Though these are often asymptomatic, but can also present with mass effect leading to dysphagia, dyspnoea, cough and stridor.

This case presented to us with respiratory distress due to tracheal compression by the ectopic thyroid mass.

\section{a) HISTORY}

A 50 year aged, hypothyroid female patient, on regular medications for the last 10 years presented with an incidentally discovered, slowly progressing, non-tender swelling in her right lower part of neck for last 10 months.

For the last 2 weeks she had complaints of occasional respiratory distress, which was more prominent in the supine position.

No complaint of dysphagia or hoarseness of voice.

\section{b) ON EXAMINATION}

No visible fullness in her neck.

On palpation, a globular lump of size $3 * 3 \mathrm{~cm}$ was felt in the lower part of the neck on the right side along the anterior border of sternocleidomastoid.

Lower border could not be appreciated.

It was non-mobile, firm in consistency with smooth surface and well-defined margins.

It was not moving with deglutition.

Percussion note over the mediastinum was dull.

Kocher's test and Pemberton sign were negative.

\section{c) INVESTIGATIONS}

Routine blood work was within normal limits.

Chest Skiagram showed deviation of the trachea to the left (Fig. 1).

'Financial or Other Competing Interest': None.

Submission 17-11-2017, Peer Review 01-12-2017,

Acceptance 16-12-2017, Published 01-01-2018.

Corresponding Author:

Dr. Bikram Haldar

1C1-25/5, Prantik Housing Complex,

Thakurpukur, Kolkata-700104.

E-mail: bikramhaldar6883@gmail.com

DOI: $10.14260 /$ jemds $/ 2018 / 26$

\section{(c) (i) $(9)$}

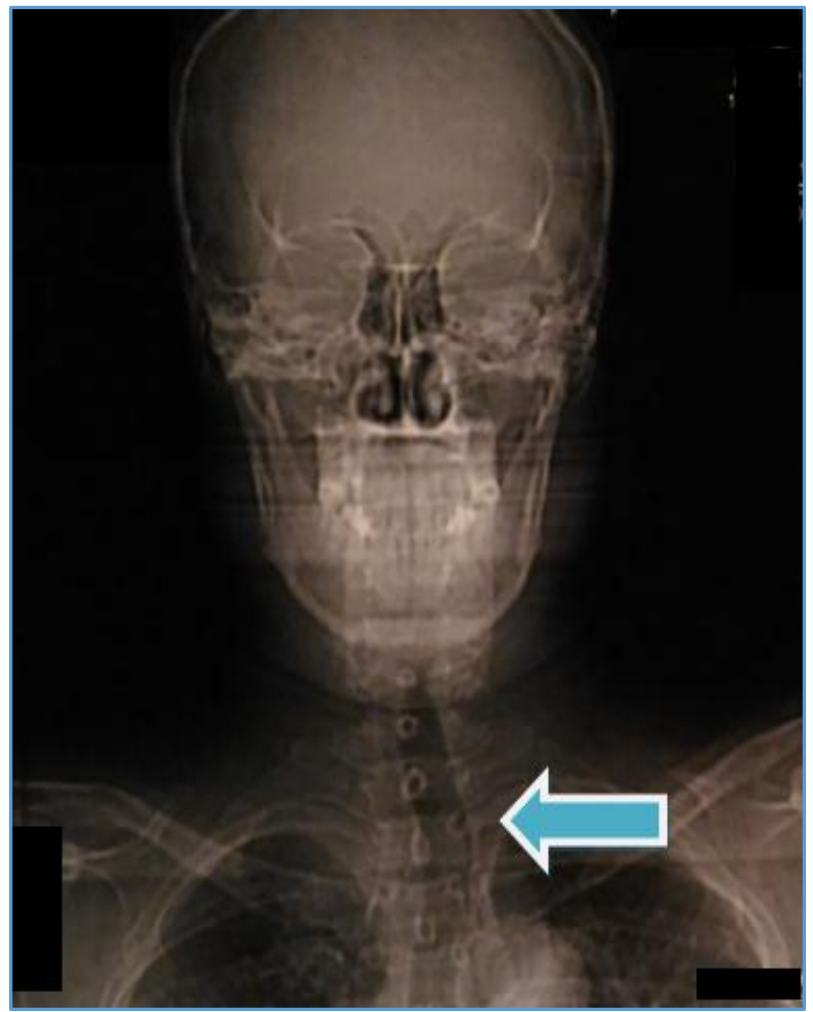

Figure 1. Skiagram of the head and neck showing deviation of the trachea to the left

USG and CT scan of the neck revealed that thyroid tissue $(33 * 38 \mathrm{~mm})$ was visualised with multiple cysts, having few septae and chunky calcifications near the right sternoclavicular junction (Fig. 2, 3). Both lobes of thyroid were not present in their orthotopic position.

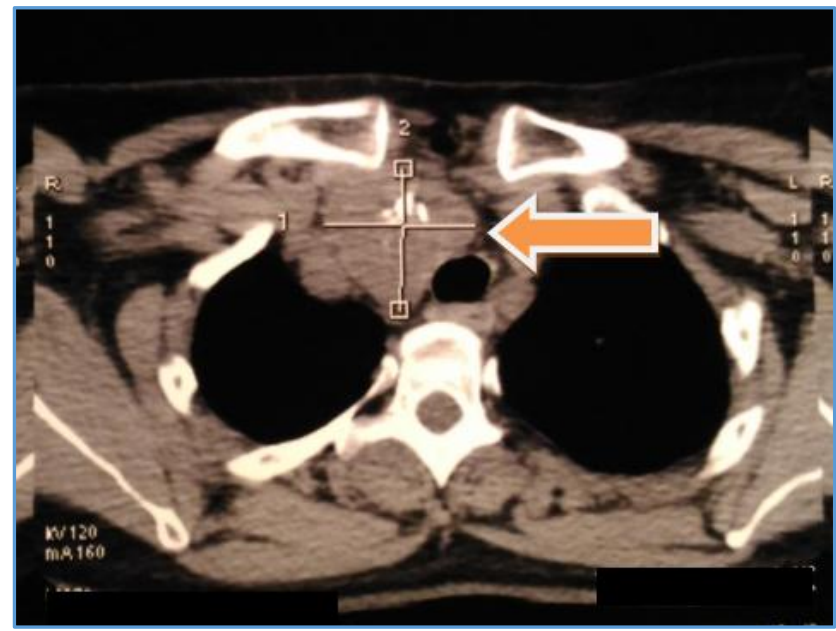

Figure 2. CECT scan of the thorax showing a mass at the retro-sternal region 


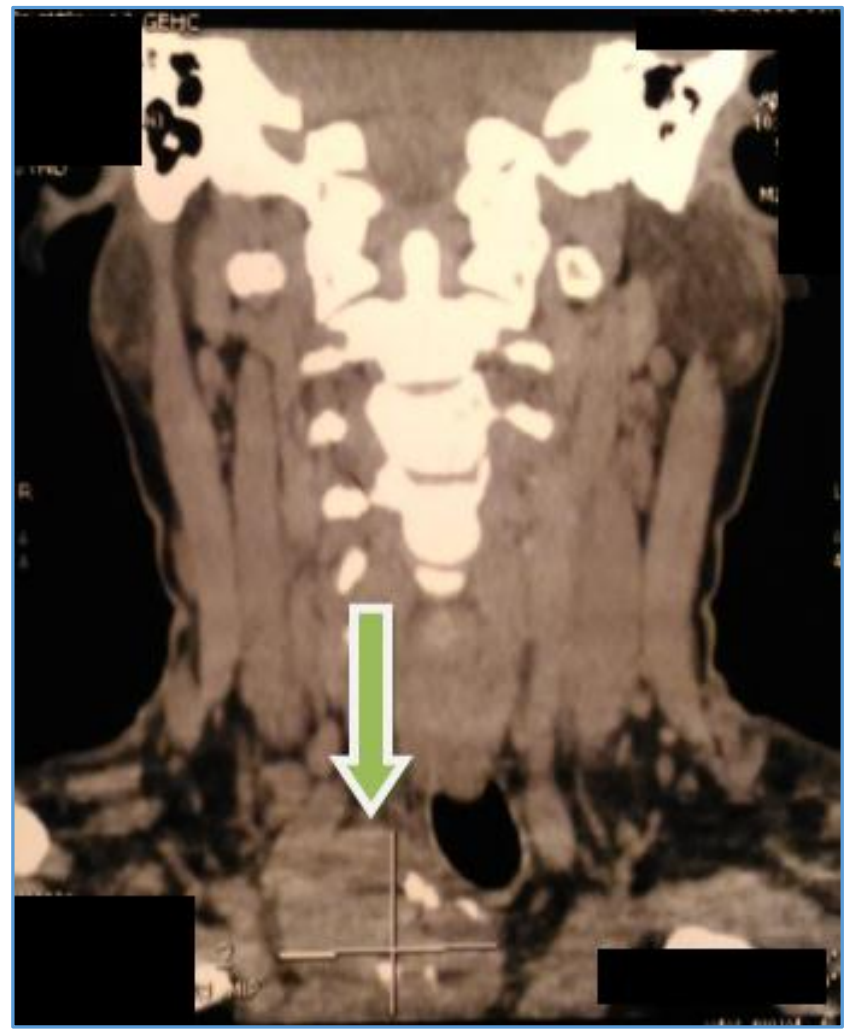

Figure 3. CECT scan of the neck showing a mass at the thoracic inlet displacing the trachea to the left

USG-guided FNAC was suggestive of colloid goitre with Bethesda score of 3 .

An MRI neck showed an altered signal intensity SOL $\left(38 * 41^{*} 47 \mathrm{~mm}\right)$, located in thoracic inlet extending into the retromanubrium space, abutting the trachea and the brachiocephalic trunk with maintained fat planes (Fig. 4).

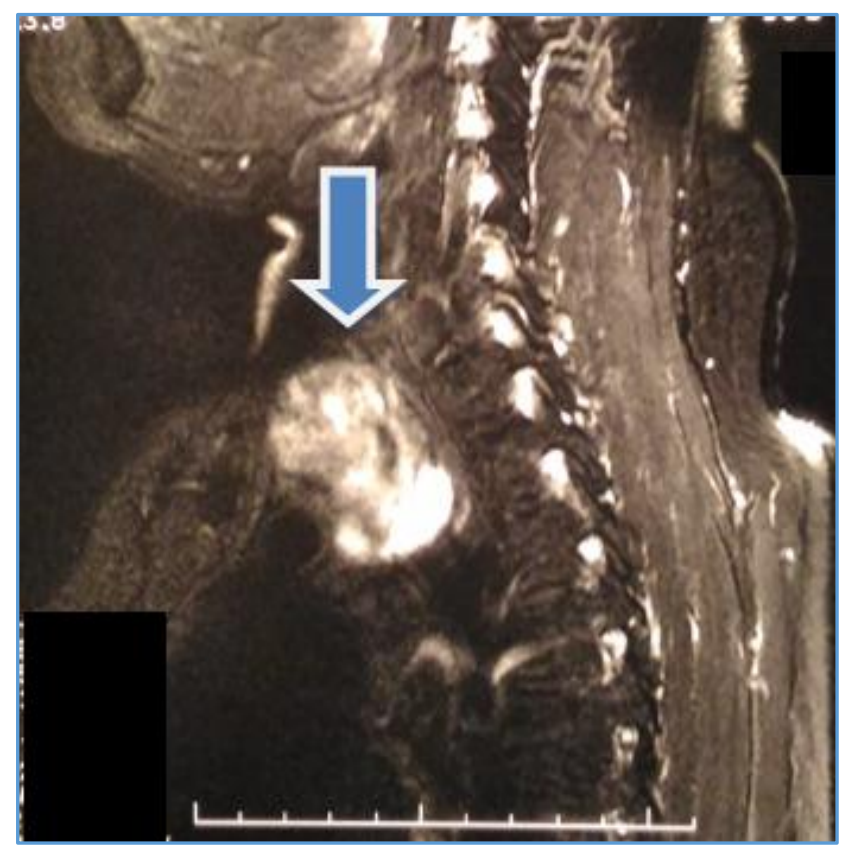

Figure 4. MRI scan of the neck and thorax showing a mass at the retro-manubrium region

\section{DIFFERENTIAL DIAGNOSES}

The Possible Differential Diagnoses of this Lump is,

a) Germ cell tumours.

b) Lymphomas.

c) Neurogenic tumours.

d) Thymic tumours.

e) Ganglioneuromas.

\section{CLINICAL DIAGNOSIS}

The clinical diagnosis of this case after all the relevant investigations was ectopic goitre in the mediastinum.

\section{DISCUSSION OF MANAGEMENT}

Under general anaesthesia, a midline sternotomy was done. The lump could not be seen in the immediate retrosternal location. When the dissection was progressed upwards, the inferior aspect of the thyroid lump was seen in the suprasternal space extending up to the retromanubrium region. There were numerous vascular twigs surrounding the lump, which were ligated and divided (Fig. 5).

On the inferior aspect, the vascular pedicle was the most prominent one with evidence of direct supply from the brachiocephalic trunk which was ligated and divided (Fig. 6).

The lesion was compressing on the trachea, so it was removed carefully with no major adhesions being encountered and was divided from the medial attachments where no other thyroid tissue could be appreciated.

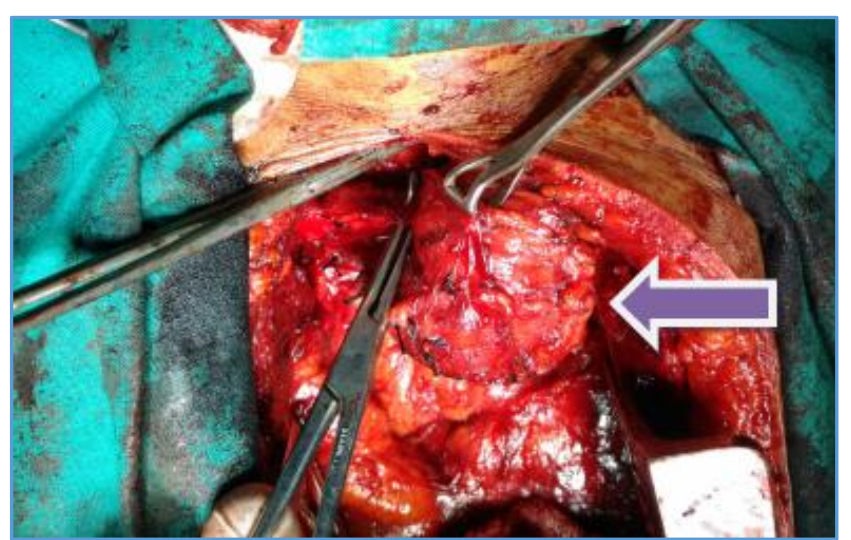

Figure 5. Intraoperative picture showing the ectopic thyroid tissue and it's vascular supplies

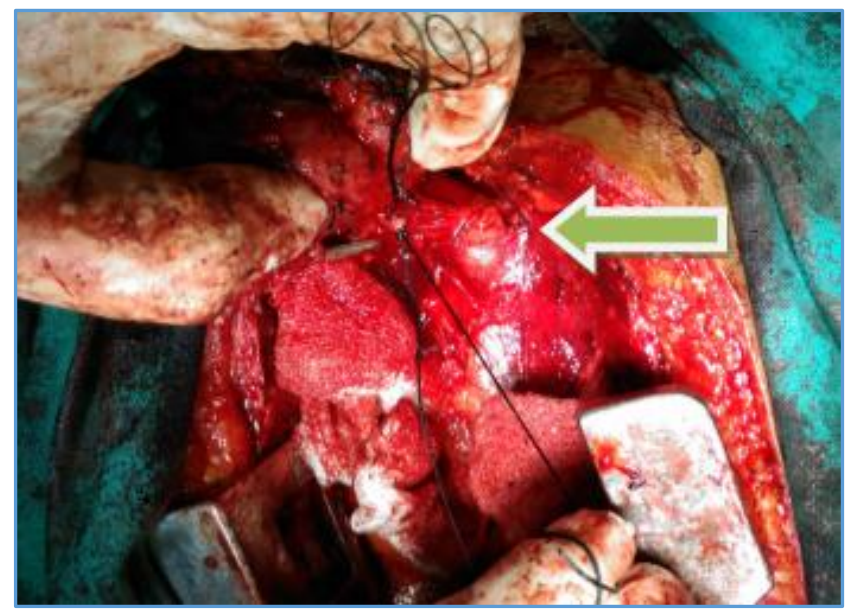

Figure 6. Intraoperative picture showing the brachiocephalic trunk and the main pedicle of the ectopic thyroid tissue arising from it 


\section{PATHOLOGICAL DISCUSSION}

Histopathology report suggested Colloid goitre with cystic degeneration and recurrent haemorrhages (Fig. 7).

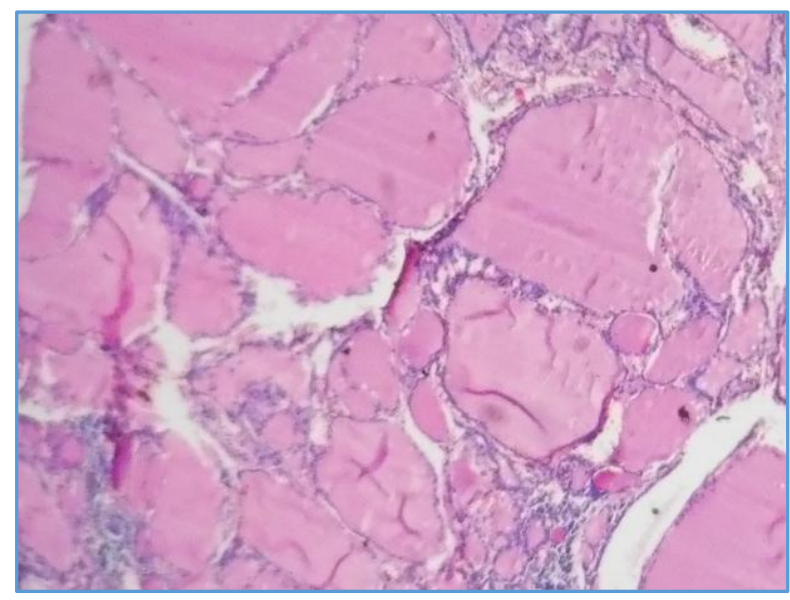

Figure 7. HPE showing colloid filled follicles

\section{FINAL DIAGNOSIS}

The final diagnosis of the case was that of a primary mediastinal ectopic goitre with vascular supply from the brachiocephalic trunk.

\section{DISCUSSION ABOUT THE CASE}

The embryological development of thyroid gives us an anatomical roadmap to predict the locations of an ectopic thyroid tissue. Lingual thyroid is the most common location (90\%).5 The other sites are sublingual, prelaryngeal, intratracheal, oesophagus, mediastinum, gall bladder, porta hepatis, salivary glands etc.

Presence of ectopic thyroid tissues at uncommon locations may be due to abnormal migration of heterotrophic differentiation of uncommitted endodermal cells. ${ }^{6}$ Over descent migration of the thyroglossal duct remnants have been proposed as the possible event leading to mediastinal ectopic thyroids. ${ }^{7}$ A primary mediastinal ectopic thyroid whose prime supply is the thoracic vessel is quite rare. 8,9 Mediastinal thyroids should be differentiated from germ cell tumours, neurogenic tumours, thymic tumours and lymphomas. ${ }^{2}$ Commonly reported symptoms are painful and pulsating retrosternal mass, cough and dyspnoea. Mostly mediastinal thyroids present with hypothyroidism, but rarely hyperthyroidism with Graves' disease have also been reported. 10

Ultrasound scan along with assistance of a radioiodine scan can help in further characterisation of the lesion. ${ }^{11}$ CT scan and MRI are mandatory for complete evaluation of site and structure of the ectopic thyroid tissue. CT and Endobronchial ultrasound guided biopsy of the lesion has been found to be useful. ${ }^{12}$

Histological analysis can help differentiate benign aetiologies from malignant ones. Surgery for mediastinal goitres should always be thought of as there is high risk of tracheal compression, malignant potential, mass effects and the low morbidity of the surgery. ${ }^{13}$ Thoracoscopic approach has been shown to be effective. 4

\section{CONCLUSION}

Here, we present a case of primary ectopic mediastinal thyroid which was symptomatic due to mass effect on the trachea and was hence surgically managed. Ectopic goitre therefore remains as one of the important differential diagnosis of a mediastinal mass. Surgical excision is the best option, considering the risk of compression of the surrounding structures and the risk of malignancy. CT and MRI scan help in delineating the anatomy and planning the surgery.

\section{REFERENCES}

[1] Gamblin TC, Jennings GR, Christie DB, et al. Ectopic thyroid. Ann Thorac Surg 2003;75(6):1952-3.

[2] Bremerich J, Pippert H. Ectopic thyroid tissue: an unusual differential diagnosis of space-occupying mediastinal lesions. Schweiz Med Wochenschr 1997;127(7):266-70.

[3] Noussios G, Anagnostis P, Goulis DG, et al. Ectopic thyroid tissue anatomical clinical and surgical implications of a rare entity. Eur J Endocrinol 2011;165(3):375-82.

[4] Grondin SC, Buenaventura P, Luketich JD. Thoracoscopic resection of an ectopic intrathoracic goiter. Ann Thorac Surg 2001;71(5):1697-8.

[5] Choi JY, Kim JH. A case of an ectopic thyroid gland at the lateral neck masquerading as a metastatic papillary thyroid carcinoma. J Korean Med Sci 2008;23(3):548-50.

[6] Ghanem N, Bley T, Altehoefer C, et al. Ectopic thyroid gland in the porta hepatis and lingua. Thyroid 2003;13(5):503-7.

[7] Harach HR. Ectopic thyroid tissue adjacent to the gallbladder. Histopathology 1998;32(1):90-1.

[8] Barbetakis N, Chnaris A, Papoulidis P, et al. Ectopic mediastinal thyroid tissue-a case report and review of the literature. Hospital Chronicles 2010;5(2):99-102.

[9] Roh E, Hong ES, Ahn HY, et al. A case of mediastinal ectopic thyroid presenting with a paratracheal mass. Korean J Intern Med 2013;28(3):361-4.

[10] Salvatori M, Rufini V, Corsello SM, et al. Thyrotoxicosis due to ectopic retrotracheal adenoma treated with radioiodine. J Nucl Biol Med 1993;37(2):69-72.

[11] Zander DA, Smoker WR. Imaging of ectopic thyroid tissue and thyroglossal duct cysts. Radiographics 2014;34(1):37-50.

[12] Madan K, Mittal S, Hadda V, et al. Endobronchial ultrasound-guided transbronchial needle aspiration of thyroid: report of two cases and systematic review of literature. Lung India 2016;33(6):682-7.

[13] de Perrot M, Fadel E, Mercier O, et al. Surgical management of mediastinal goiters: when is a sternotomy required? Thorac Cardiovasc Surg 2007;55(1):39-43. 